\title{
Wettability Alteration of Sandstone by Chemical Treatments
}

\author{
Yan-ling Wang, ${ }^{1}$ Li Ma, ${ }^{1}$ Bao-jun Bai, ${ }^{2}$ Guan-cheng Jiang, ${ }^{3}$ \\ Jia-feng Jin, ${ }^{1}$ and Zeng-bao Wang ${ }^{1}$ \\ ${ }^{1}$ Petroleum Engineering College, Petroleum University of China, Qingdao Shandong 266555, China \\ ${ }^{2}$ Petroleum Engineering, Missouri University of Science and Technology, Rolla, MO 65409-0410, USA \\ ${ }^{3}$ Key Laboratory of Petroleum Engineering of Education Ministry in China University of Petroleum, Beijing 102249, China
}

Correspondence should be addressed to Yan-ling Wang; wangyl_hdpu@hotmail.com and Bao-jun Bai; baib@mst.edu

Received 25 June 2013; Accepted 13 August 2013

Academic Editor: Yujun Feng

Copyright (C) 2013 Yan-ling Wang et al. This is an open access article distributed under the Creative Commons Attribution License, which permits unrestricted use, distribution, and reproduction in any medium, provided the original work is properly cited.

\begin{abstract}
Liquid condensation in the reservoir near a wellbore may kill gas production in gas-condensate reservoirs when pressure drops lower than the dew point. It is clear from investigations reported in the literature that gas production could be improved by altering the rock wettability from liquid-wetness to gas-wetness. In this paper, three different fluorosurfactants FG1105, FC911, and FG40 were evaluated for altering the wettability of sandstone rocks from liquid-wetting to gas-wetting using contact angle measurement. The results showed that FG40 provided the best wettability alteration effect with a concentration of $0.3 \%$ and FC911 at the concentration of $0.3 \%$.
\end{abstract}

\section{Introduction}

The wettability of the reservoir is not only a key factor for controlling the flow of reservoir fluids into the porous media, but it also had a great effect on both the relative permeability values of the liquid and gas phases and recovery $[1,2]$. The wettability of the reservoir would be altered adversely if the liquid for drilling and production were not adequate. This would damage the reservoir and reduce production $[2,3]$. Therefore, it has become a very important task in the field of petroleum and surface chemistry, at home and abroad, to improve the recovery and protection of oil and gas. Recently, with the development of gas reservoirs and gas-condensation reservoirs, a study of "gas wetness" was proposed by $\mathrm{Li}$ and Firoozabadi in 2000 [4]. A new method was introduced for recovering productivity in gas wells by altering wettability in gas-condensation reservoirs from liquid-wetting to intermediate gas-wetting. A substantial increase in gas well delivery and oil recovery would show when the wettability of a reservoir was altered from strong liquid wetness to the preferred gas wetness [4-7].

In Li and Firoozabadi's work, the alteration of wettability was achieved by treating the rocks with the chemical solutions FC754 and FC722 [5]. Significant changes in the wettability were demonstrated by imbibition tests and capillary tube tests. The contact angle of the gas-water systems increased to about $90^{\circ}$ from $50^{\circ}$, and the contact angle of the gas-oil systems increased to about $60^{\circ}$ from $0^{\circ}$, at a concentration of approximately $0.1 \%$, showing that the gas-wetting was not as strong as expected. FC722 was more effective than FC754 in altering wettability in the gas-liquid-Berea systems, but it was difficult to use because FC722 is neither soluble in water nor in oil.

Tang and Firoozabadi [7] altered the wettability of Berea and Chalk from liquid-wetting to intermediate gas-wetting using two polymers, FC722 and FC759. All the results showed clearly that the application of wettability alteration to intermediate gas-wetting may significantly increase deliverability in gas condensation reservoirs.

Yao et al. [8] studied the ability and characteristics of sodium dodecyl sulfate, CTAB, OP-15, Dimethyl silicone oil, and dimethyldichlorosilane in altering the wettability of synthetic sandstone from liquid-wetting to intermediate gaswetting. Dimethyl silicone oil and dimethyldichlorosilane were found to be very effective for altering the wettability of gas-liquid-sandstone systems.

Liu et al. [9] changed the wettability of the rock from water-wetness to gas-wetness effectively by using a new and 
TABLE 1: Contact angle of the sandstone after treated with FG1105.

\begin{tabular}{lccccc}
\hline Concentration of FG1105 (\%) & 0.05 & 0.1 & 0.2 & 0.3 & 0.5 \\
\hline $\begin{array}{l}\text { Contact angle }\left({ }^{\circ}\right) \\
\quad \text { Brine }\end{array}$ & 50 & 45 & 46 & 42 & 36 \\
$\quad$ Normal decane & 10 & 10 & 0 & 0 & 0 \\
\hline
\end{tabular}

TABLE 2: Contact angle of the sandstone after treated with FC911.

\begin{tabular}{lcccccc}
\hline Concentration of FC911 (\%) & 0 & 0.1 & 0.2 & 0.3 & 0.5 & 1 \\
\hline Contact angle $\left(^{\circ}\right)$ & & & & & & \\
$\quad$ Brine & 43 & 65 & 72 & 80 & 40 & 40 \\
$\quad$ Normal decane & 12 & 64 & 68 & 74 & 52 & 76 \\
\hline
\end{tabular}

TABLE 3: Contact angle of the sandstone after treatment with FG40.

\begin{tabular}{lcccccc}
\hline Concentration of FG40 (\%) & 0 & 0.05 & 0.1 & 0.2 & 0.3 & 0.5 \\
\hline Contact angle $\left(^{\circ}\right)$ & & & & & & \\
$\quad$ Brine & 40 & 93 & 142 & 134 & 140 & 130 \\
$\quad$ Normal decane & 10 & 75 & 88 & 89 & 93 & 84 \\
\hline
\end{tabular}

cheaper chemical, WA12. Aspontaneous water imbibition test and a flooding test were run to show the effect of wettability alteration on recovery.

However, in the above studies, the contact angle of the gas-water systems increased to only about $90^{\circ}$ and the contact angle of the gas-oil systems increased to only about $60^{\circ}$. Hydrocarbon surfactants, cationic fluorosurfactants, organic silicon, and polymers were evaluated for their ability to alter the wettability of rocks from liquid wetness to gas wetness.

In this paper, three fluorosurfactants, FG1105, FC911, and FG40 were used to alter the wettability of the sandstone from liquid-wetting to gas-wetting for the first time. FG1105 and FG40 are nonionic fluorosurfactants. FC911 is a cationic fluorosurfactant. In order to evaluate their ability to alter the wettability of sandstone to gas wetness, the contact angle for gas-water-sandstone systems and gas-oil-sandstone systems were measured by a contact angle meter using the sessile drop method. In addition, the effects of a concentration of chemicals on gas wetness are discussed in this work.

\section{Experimental}

2.1. Apparatus. The contact angles were measured using the sessile drop method by a Powereach JY-82 Contact Angle Meter provided by Shanghai Zhongchen Digital Technology Apparatus Co. Ltd.

2.2. Fluids and Rocks. Normal decane was used as oil phase with specific gravity and viscosity of 0.73 and $0.92 \times 10^{-3} \mathrm{~Pa} \cdot \mathrm{s}$ at $25^{\circ} \mathrm{C}$, respectively. The surface tension of air-normal decane was $0.0234 \mathrm{~N} / \mathrm{m}\left(25^{\circ} \mathrm{C}\right)$. Brine of $0.2 \%$ (wt) $\mathrm{NaCl}$ was used as water phase with specific gravity and viscosity 1.012 and $1.0 \times 10^{-3} \mathrm{~Pa} \cdot \mathrm{s}\left(25^{\circ} \mathrm{C}\right)$, respectively. The surface tension of air-brine was $0.0728 \mathrm{~N} / \mathrm{m}\left(25^{\circ} \mathrm{C}\right)$. Sandstone cores from Shengli reservoir were used as the rock samples.
2.3. Chemicals. CTAB, OP-10, and dodecyl sulfate were provided by Sinopharm Chemical Reagent Co. Ltd. FG1105, FC911, and FG40 were provided by Shanghai Institute of Organic Chemistry, Chinese Academy of Sciences. FG1105 and FG40 were nonionic surfactants and FC911 [10] was cationic surfactant.

2.4. Procedure. The cores were cut to slices of approximately $2.5 \mathrm{~cm}$ in diameter and $1 \mathrm{~cm}$ in length. The sandstone chips were washed with tap water and rinsed with distilled water after cutting, placed in an oven at $120^{\circ} \mathrm{C}$ for 4 days to dry, and then soaked in the solution of fluorosurfactants (FC911, $\mathrm{FG} 40$, or FG1105) for 10 hours at $25^{\circ} \mathrm{C}$. The core slices were pulled from the solution and dried at $25^{\circ} \mathrm{C}$. This procedure produced core surfaces of altered wettability [11].

Sessile drop contact angle measurements were performed using a JY-82 Contact Angle Meter. Each core after treatment was put on the meter. In actual experiments, a drop of liquid approximately $0.3 \mathrm{~cm}$ radius was carefully deposited on the surface of each core using a gas-tight Hamilton syringe with a stainless steel needle. A picture of the drop was then typically recorded by the computer. Normally, at least three contact angle measurements were performed on a new solid surface each time. Then the contact angle could be calculated by a computer according to the pictures. All readings were then averaged to give an average contact angle [12].

\section{Results}

The mean contact angles of the gas-water systems and those of the gas-oil systems of the sandstones after treatment with FG1105 are shown in Table 1. It can be seen that FG1105 did not alter the wettability of rock to gas-wetting.

The mean contact angles of the gas-water systems and the contact angles of the gas-oil systems of the sandstone, after treatment with FC911 are shown in Table 2. It can be seen that, with the increasing of FC911 concentration, the contact angle of the gas-water systems increased from $0^{\circ}$ to $80^{\circ}$, while the contact angle of the gas-oil systems increased to $74^{\circ}$ at a concentration of $0.3 \%$. This implies that wettability of the sandstone was altered to intermediate gas-wetting by FC911 at a concentration of $0.3 \%$. And then, as the concentration continued to increase, the contact angle of the gas-water systems suddenly decreased to $40^{\circ}$, and the contact angle of the gas-oil systems decreased to $52^{\circ}$ at a concentration of $0.5 \%$. Pictures of liquid droplets on the surface of the sandstone cores, before and after treatment with FC911 at different concentrations, are shown in Figures 1 and 2. It can be seen that liquid droplets were not spread on the surface of the gas-wetting sandstone cores.

Table 3 shows the mean contact angle of the gas-water systems and the contact angle of the gas-oil systems of the sandstone after treatment with FG40. It can be seen that the wettability of the cores treated with FG40 were effectively altered to gas-wetting. It should be noted that the observed trends in the contact angle of the sandstone treated with FG40 were similar to those of sandstone treated with FC911, which was different from results in Li's work [5]. The contact 


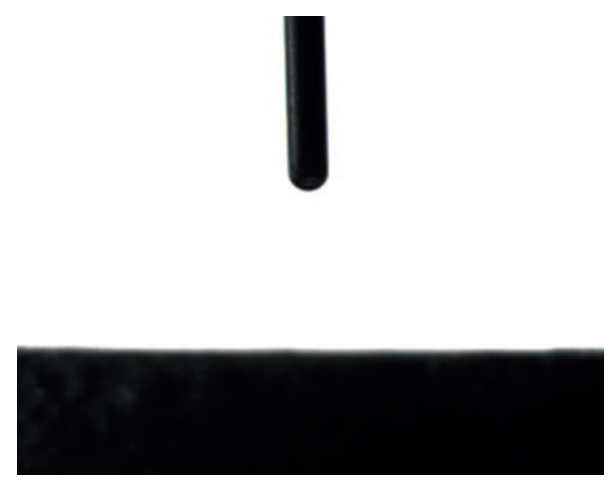

(a) Water (without chemical treatment)

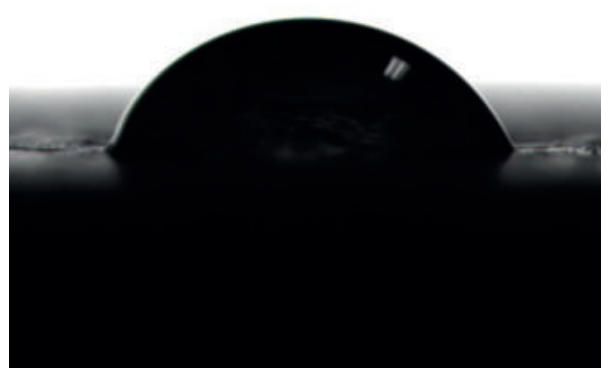

(c) Water (treated with $0.2 \%$ FC911, $\theta=72^{\circ}$ )

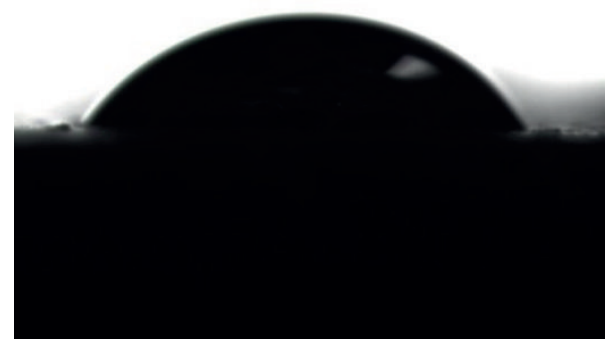

(e) Water (treated with $0.5 \%$ FC911, $\theta=40^{\circ}$ )

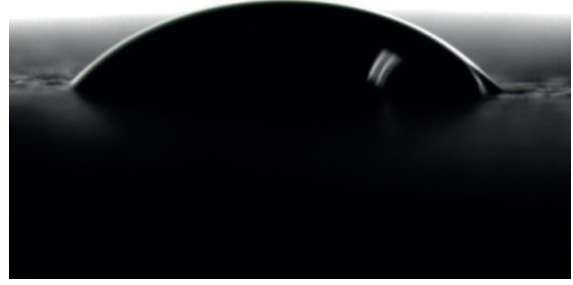

(b) Water (treated with $0.1 \%$ FC911, $\theta=65^{\circ}$ )

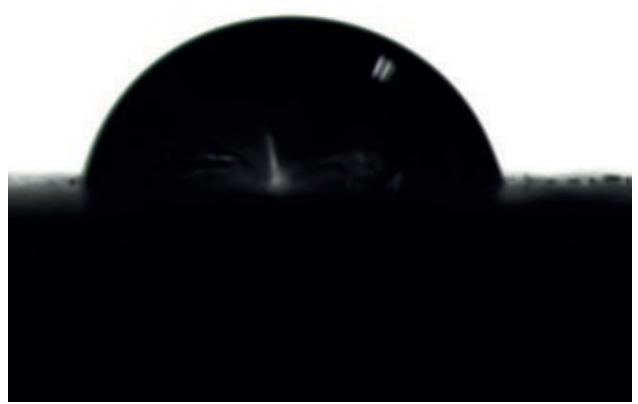

(d) Water (treated with $0.3 \%$ FC911, $\theta=80^{\circ}$ )

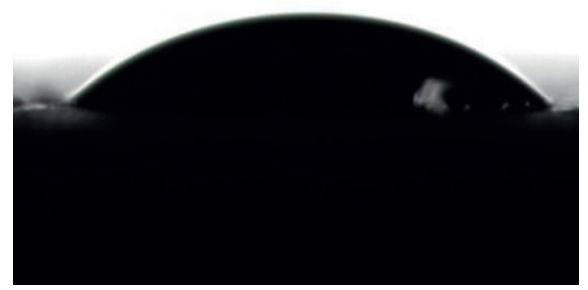

(f) Water (treated with $1.0 \%$ FC911, $\theta=40^{\circ}$ )

FIGURE 1: Water droplets on the surface of the sandstone cores before and after treatment with FC911.

angle increased with the increase of the concentration and then decreased when the concentration reached $0.3 \%$. The contact angle of the gas-water systems increased to $140^{\circ}$ and the contact angle of the gas-oil systems increased to $93^{\circ}$ at a concentration of about $0.3 \%$. This implies that the strongest gas-wetting can be obtained using FG40 at a concentration of $0.3 \%$. Liquid droplets on the surface of the sandstone cores, before and after treatment with FG40 at different concentrations, are shown in Figures 3 and 4 . It can be seen that liquid droplets were not spread on the surfaces of all of the sandstone cores that had been treated with FG40.

As the concentration of FG40 increased from 0 to $0.5 \%$, the contact angle of the gas-water systems increased from $40^{\circ}$ to $93^{\circ}$, and the contact angle of the gas-oil systems increased from $10^{\circ}$ to $75^{\circ}$. This implies that wettability of the sandstone was altered to intermediate gas-wetting by FG40. With the increase of surfactant concentration, the contact angle continued to increase as well. At the concentration of $0.3 \%$, the contact angle with the gas-water systems reached up to $140^{\circ}$ and the gas-oil systems up to $93^{\circ}$. After that, the contact angle decreased with the increase of concentration.

\section{Discussion}

All of the three chemicals used in our study are fluorosurfactants with fluorocarbon groups. The fluorosurfactants have the highest surface activity of all of the surfactants identified so far [13]. The fluorochemical group provided 


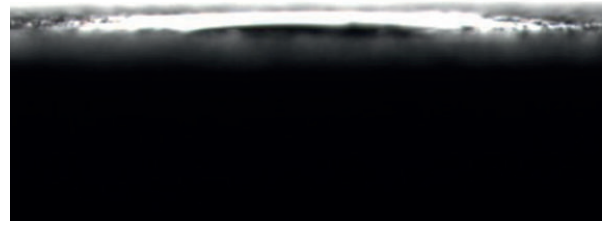

(a) Oil (without chemical treatment)

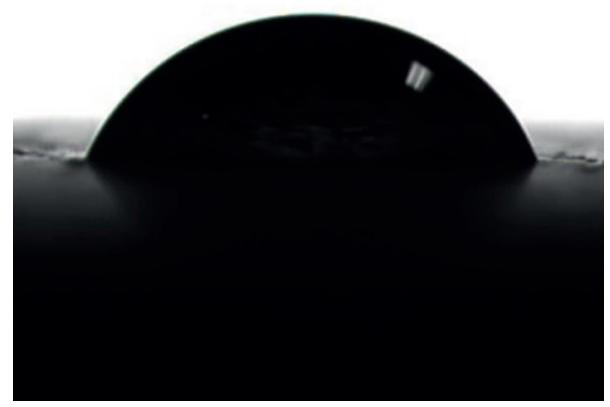

(c) Oil (treated with $0.2 \%$ FC911, $\theta=68^{\circ}$ )

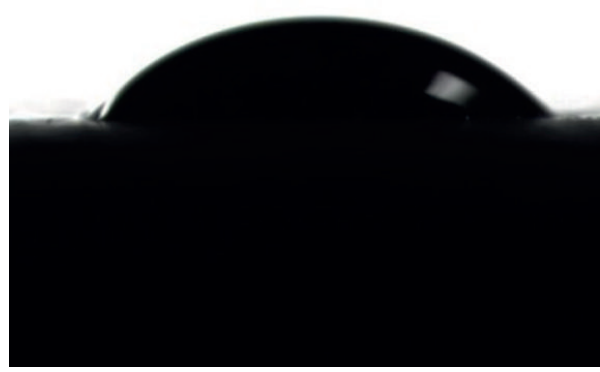

(e) Oil (treated with $0.5 \%$ FC911, $\theta=52^{\circ}$ )

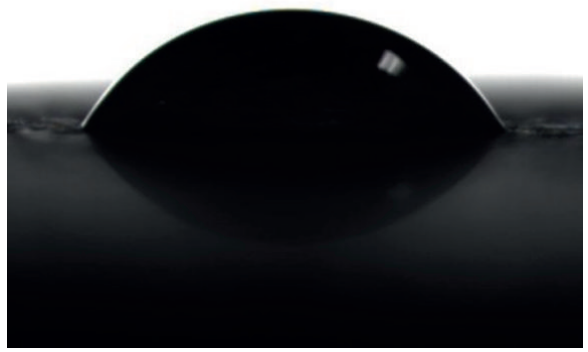

(b) Oil (treated with $0.1 \%$ FC911, $\theta=64^{\circ}$ )

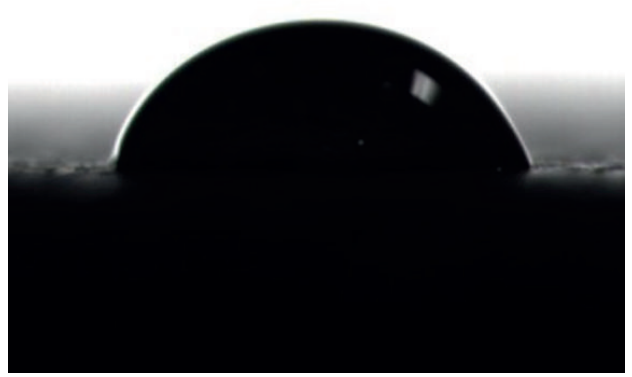

(d) Oil (treated with $0.3 \%$ FC911, $\theta=74^{\circ}$ )

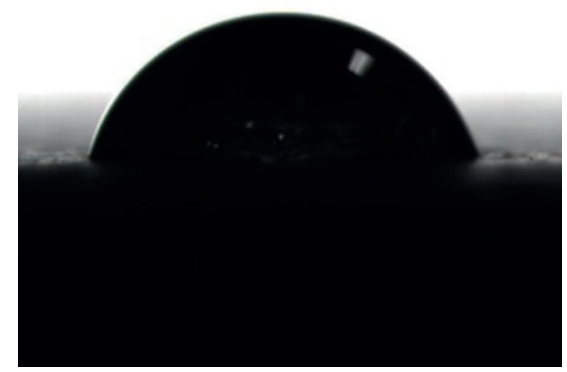

(f) Oil (treated with $1.0 \%$ FC911, $\theta=76^{\circ}$ )

Figure 2: Oil droplets on the surface of the sandstone cores before and after treatment with FC911.

the water and oil repellency; the cationic and nonionic groups chemically bonded onto the rock surfaces providing a surfacial treatment; the cationic and nonionic groups made the surfactant hydrophilically soluble [14].

The fluorocarbon group provided the water and oil repellency because it had a small van der Waals force between the fluorine and the carbon [15]. Fluorine atoms had a very strong electronegativity of 4.0. On the contrary, fluorocarbon molecules were extremely resistant to oxidation because fluorine atoms, with an electronegativity of 4.0 , were attached to their carbon atoms, thereby bringing the carbon atoms into a more oxidized state than that of those bound to the oxygen atoms of an electronegativity of 3.6. Halogens were generally strongly electronegative with high bond energy between carbon and fluorine (in particular) which had the strongest bond energy at $484 \mathrm{~kJ} / \mathrm{mol}$. Moreover, fluorine atoms were small in size (next to the smallest hydrogen atoms) and their van der Waals and covalent bond radii were larger than those of the hydrogen atoms by only $10 \%$, or so. This rather small difference in size caused the hydrocarbon chains to have a zigzag structure and the fluorocarbon chains to have a rigid rod-like shape with a period of twist with 13 carbon atoms. In addition, the carbon skeleton (within this rigid structure) was covered by densely packed fluorine atoms that were attached to the carbon atoms, much like a rod with a fluorine sheath on it [16]. The protective action of the fluorine atoms is shown in Figure 5.

The nature of fluorine atom leads to the water and oil repellency characteristic of the fluorosurfactants. Fluorine atom has the strongest electronegativity and the smallest 


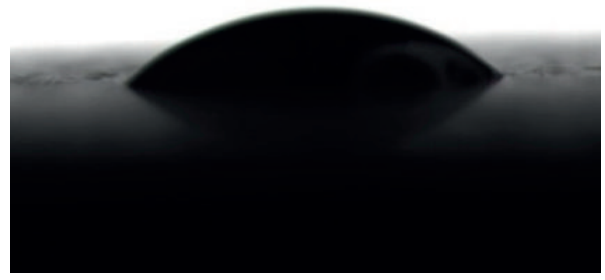

(a) Water (without chemical treatment, $\theta=40^{\circ}$ )

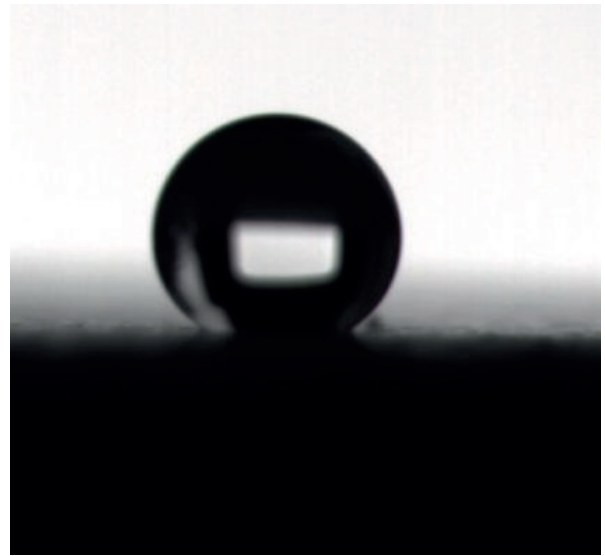

(c) Water (treated with $0.1 \% \mathrm{FG} 40, \theta=142^{\circ}$ )

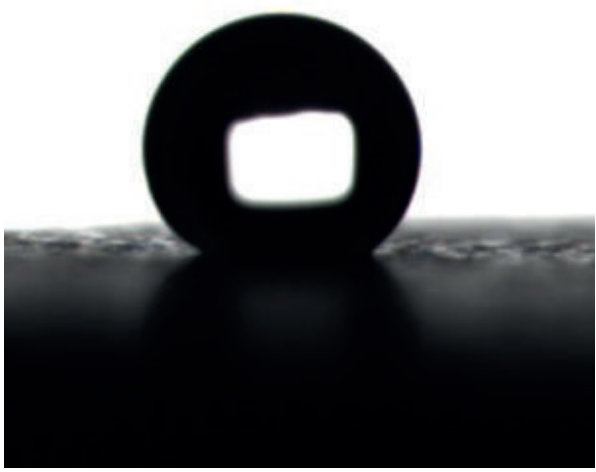

(e) Water (treated with $0.3 \% \mathrm{FG} 40, \theta=140^{\circ}$ )

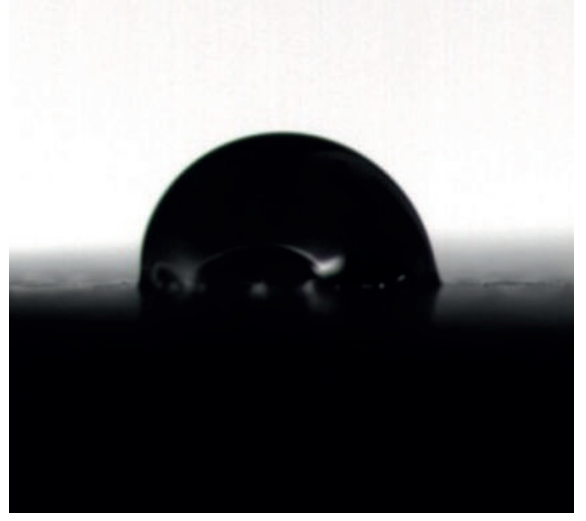

(b) Water (treated with $0.05 \%$ FG40, $\theta=93^{\circ}$ )

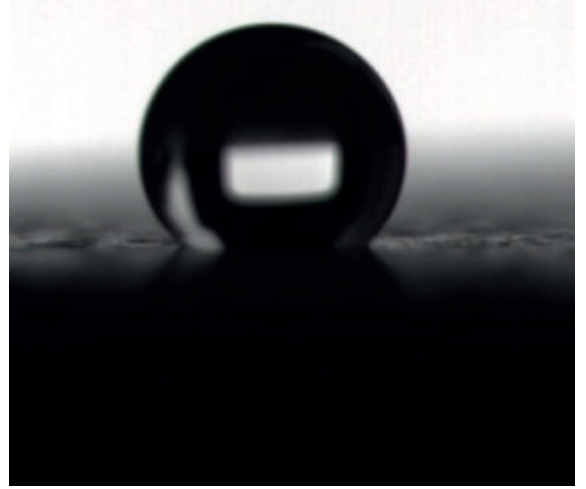

(d) Water (treated with $0.2 \%$ FG40, $\theta=134^{\circ}$ )

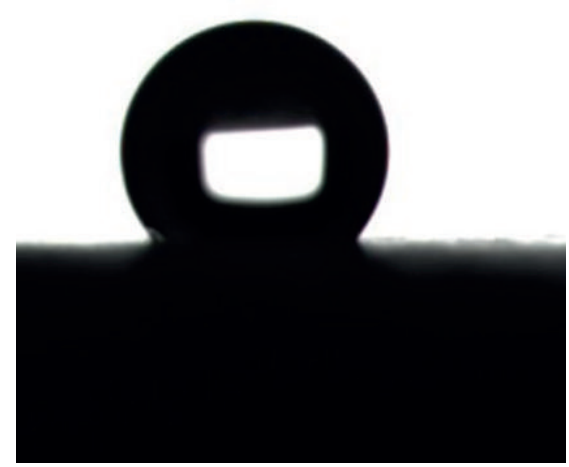

(f) Water (treated with $0.5 \%$ FG40, $\theta=130^{\circ}$ )

FIGURE 3: Water droplets on the surface of the sandstone cores before and after treatment with FG40.

atomic polarizability among the elements. Its atom radius is also smaller than other elements except for hydrogen. This enables the formation of a strong carbon-fluorine bond thereby forming the perfluoroalkyl group having weak intermolecular Van der Waals force and small interaction with other substances such as water and hydrocarbons. Then, the surfaces of the cores were altered to gas-wetting because of the water and oil repellency characteristic of the fluorosurfactants.
In Li's study [5], the contact angle was measured by a capillary tube test. Li found that the contact angle increased when the concentration of chemicals increased and then remained constant when the concentration increased to a certain value. After that, the gas-wetting remained the same with an increase in concentration. However, our findings are different from Li's results. Our results illustrate that the strongest gas-wetting of the surface of cores will appear at optimistic concentration of surfactants as shown in 


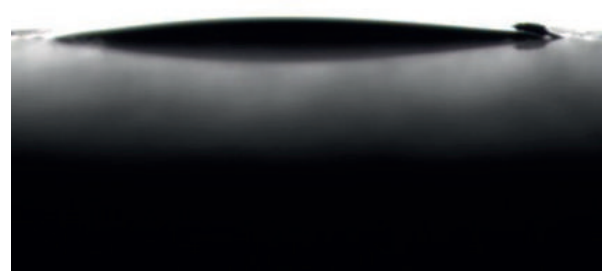

(a) Oil (without chemical treatment, $\theta=10^{\circ}$ )

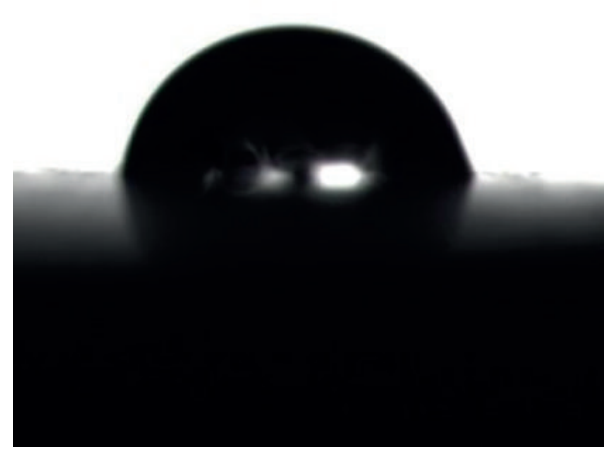

(c) Oil (treated with $0.1 \%$ FG40, $\theta=88^{\circ}$ )

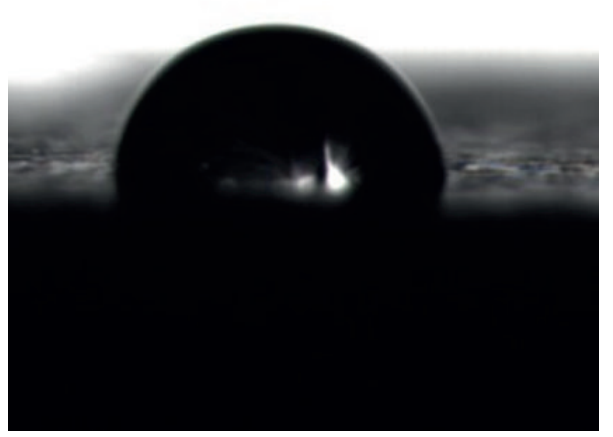

(e) Oil (treated with $0.3 \% \mathrm{FG} 40, \theta=93^{\circ}$ )

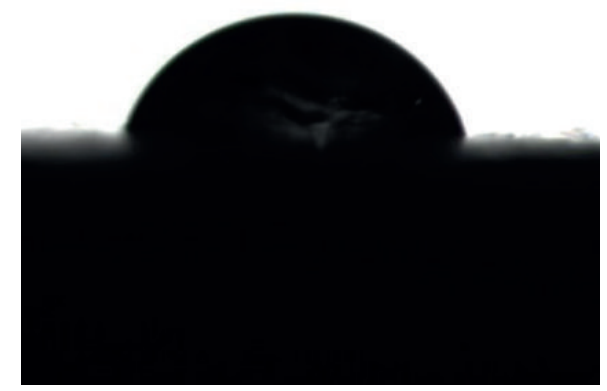

(b) Oil (treated with $0.05 \% \mathrm{FG} 40, \theta=75^{\circ}$ )

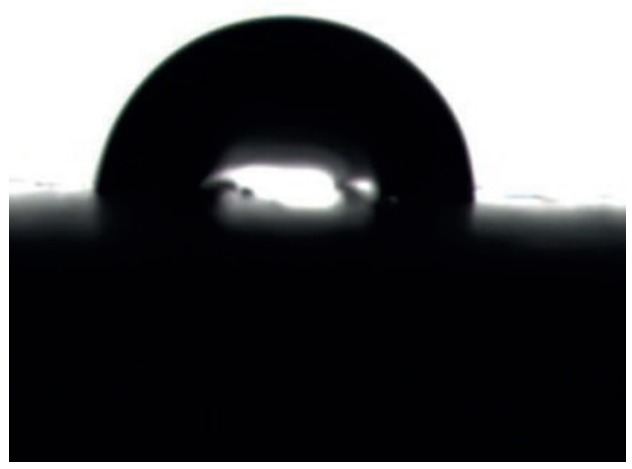

(d) Oil (treated with $0.2 \% \mathrm{FG} 40, \theta=89^{\circ}$ )

FIGURE 4: Oil droplets on the surface of the sandstone cores before and after treatment with FG40.

Table 3. The reduction in the gas-wetting may be due to the double-layer adsorption of the chemical $[17,18]$. As shown in Figure 6, after the surface of the core is saturated by the adsorption of surfactant molecules, moleculars will adsorb and spread on the surfactants film through hydrophobic interactions with hydrophilic groups outward. Thus, the gaswetting of the surface decreased, the water-wetting became stronger, and the contact angles decreased as the concentration increased.

\section{Conclusions}

The effectiveness of three fluorosurfactant treatments in altering reservoir core wettability from liquid-wetting to 


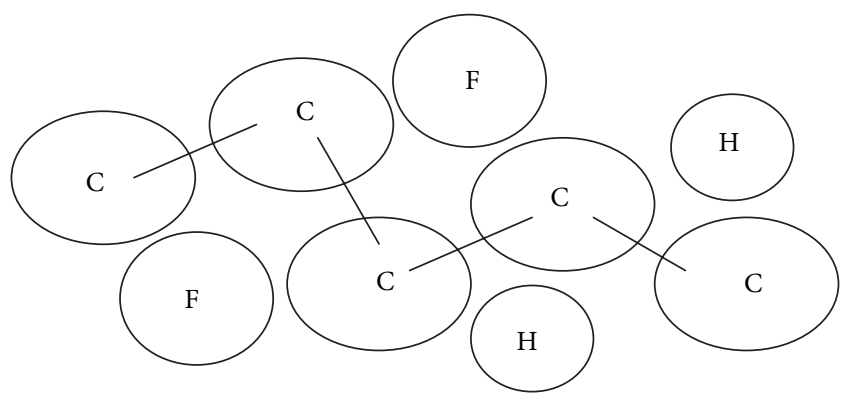

Figure 5: Protective action of fluorine atoms.

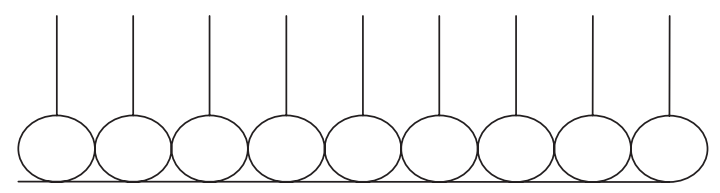

Surface of rock

Fluorocarbon surfactant

(a) Single-layer adsorption
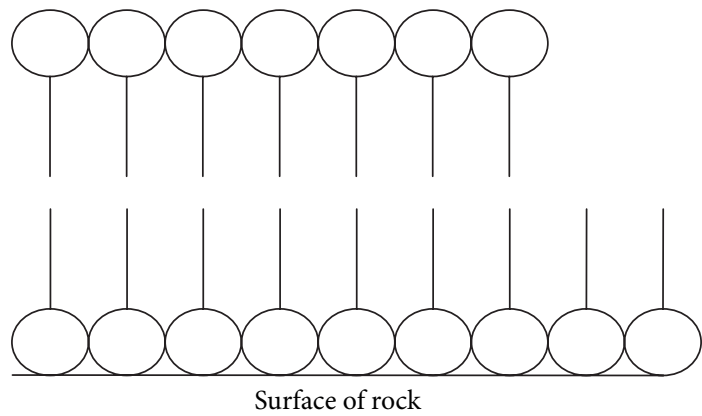

Fluorocarbon surfactant

(b) Double-layer adsorption

Figure 6: Adsorption of the Fluorocarbon Surfactant on the Surface of Rock.

intermediate gas-wetting was assessed. No significant improvement was observed after treating sandstone cores with FG1105. A $0.3 \%$ FC119 solution was found to effectively change the wettability of the sandstone rocks from preferential liquid-wetness to gas-wetness. FG40 had a better effect in altering reservoir core wettability from liquid wetting to intermediate gas wetting, with a very low concentration ranging from $0.05 \%$ to $0.5 \%$. The contact angle increased with the increase of the concentration and then decreased when the concentration reached $0.3 \%$. This was because of the adsorption of chemical changes from single-layer to doublelayer with the increase in concentration.

\section{Acknowledgments}

We gratefully acknowledge the financial support from the Natural Foundation for Outstanding Youth of China
(50925414), the Project of Science and Technology Development of Shandong Province (2010GSF10601), the Research Award Fund for Young Scientist of Shandong Province (BS2009CL019), the National Oil \& Gas Key Special Project of China (2011ZX05005-006-007HZ), and the Fundamental Research Funds for the Central Universities.

\section{References}

[1] J. Yan, "Effect of rock wettability on oil recovery by waterflooding," Journal of the University of Petroleum, vol. 22, no. 3, pp. 43-46, 1998.

[2] H. Chun, T. Zhiqiang, and J. Guancheng, "Effect of wettability on water injection recovery factor of heavy oil reservoir of Kendong Block 29," Oil Drilling \& Production Technology, vol. 21, no. 3, pp. 92-94, 1999.

[3] R. S. Barnum, F. P. Brinkman, T. W. Richardson, and A. G. Spillette, "Gas condensate reservoir behaviour: productivity and recovery reduction due to condensation," in Proceedings of the SPE Annual Technical Conference and Exhibition, vol. 30767, pp. 677-687, Dallas, Tex, USA, October 1995.

[4] K. Li and A. Firoozabadi, "Phenomenological modeling of critical condensate saturation and relative permeabilities in gas/condensate systems," SPE Journal, vol. 5, no. 2, pp. 138-147, 2000.

[5] K. Li and A. Firoozabadi, "Experimental study of wettability alteration to preferential gas-wetting in porous media and its effects," SPE Reservoir Evaluation and Engineering, vol. 3, no. 2, pp. 139-149, 2000.

[6] A. Delavarmoghaddam, S. A. Mirhaj, and P. L. J. Zitha, "Gas condensate productivity improvement by chemical wettability alteration," in Proceedings of the 8th European Formation Damage Conference, vol. 122225, pp. 27-29, Scheveningen, The Netherlands, May 2009.

[7] G.-Q. Tang and A. Firoozabadi, "Relative permeability modification in gas/liquid systems through wettability alteration to intermediate gas wetting," SPE Reservoir Evaluation and Engineering, vol. 5, no. 6, pp. 427-436, 2002.

[8] T.-Y. Yao, J.-S. Li, and F.-Y. Yao, "Effects of gas-wetting on porous flow behavior in gas-condensate reservoirs," Oilfield Chemistry, vol. 25, no. 2, pp. 101-104, 2008.

[9] Y. Liu, H. Zheng, G. Huang, G. Li, and K. Li, "Production enhancement in gas-condensate reservoirs by altering wettability to gas wetness: field application," in Proceedings of the 16th SPE/DOE Improved Oil Recovery Symposium (IOR '08), vol. 99739, pp. 175-181, Tulsa, Okla, USA, April 2008.

[10] X. Wang and Z. Shi, "Fluoro surfactant," Fine and Specialty Chemicals, no. 24, pp. 14-15, 1999.

[11] D. Y. Kwok and A. W. Neumann, "Contact angle measurement and contact angle interpretation," Advances in Colloid and Interface Science, vol. 81, no. 3, pp. 167-249, 1999.

[12] D. Y. Kwok, R. Lin, M. Mui, and A. W. Neumann, "Low-rate dynamic and static contact angles and the determination of solid surface tensions," Colloids and Surfaces A, vol. 116, no. 12, pp. 63-77, 1996.

[13] A. H. Ahlbrecht and B. T. White, "Fluorocarbon sulfonamide alkanols and Sulfates Thereof," USP, 2803656, 1957.

[14] J. G. Linert, "A new water-soluble fluoropolymer silanol and its application in stone and concrete protection," in Proceedings of the Waterborne, High-Solids, and Powder Coating Symposium, 1997. 
[15] W. Jiang, Special surfactants, Beijing Light Industrial Press, Beijing, China, 1995.

[16] M. Abe, "Synthesis and applications of surfactants containing fluorine," Current Opinion in Colloid and Interface Science, vol. 4, no. 5, pp. 354-356, 1999.

[17] Z. Bi, Y. Shi, W. Yan, and J. Yu, "Adsorption of cetyl trimethylamm on ium bromide on surface of silicon dioxide," Huaxue Shiji, vol. 19, no. 6, pp. 331-333, 1997.

[18] W. A. Ducker and E. J. Wanless, "Adsorption of hexadecyltrimethylammonium bromide to mica: nanometer-scale study of binding-site competition effects," Langmuir, vol. 15, no. 1, pp. 160-168, 1999. 

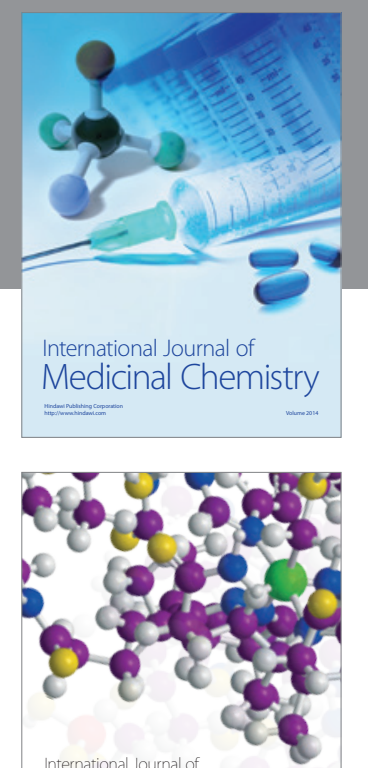

\section{Carbohydrate} Chemistry

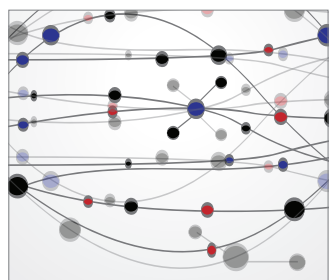

The Scientific World Journal
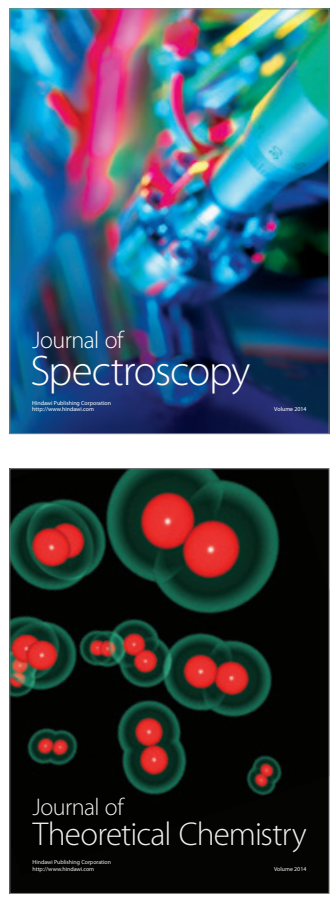
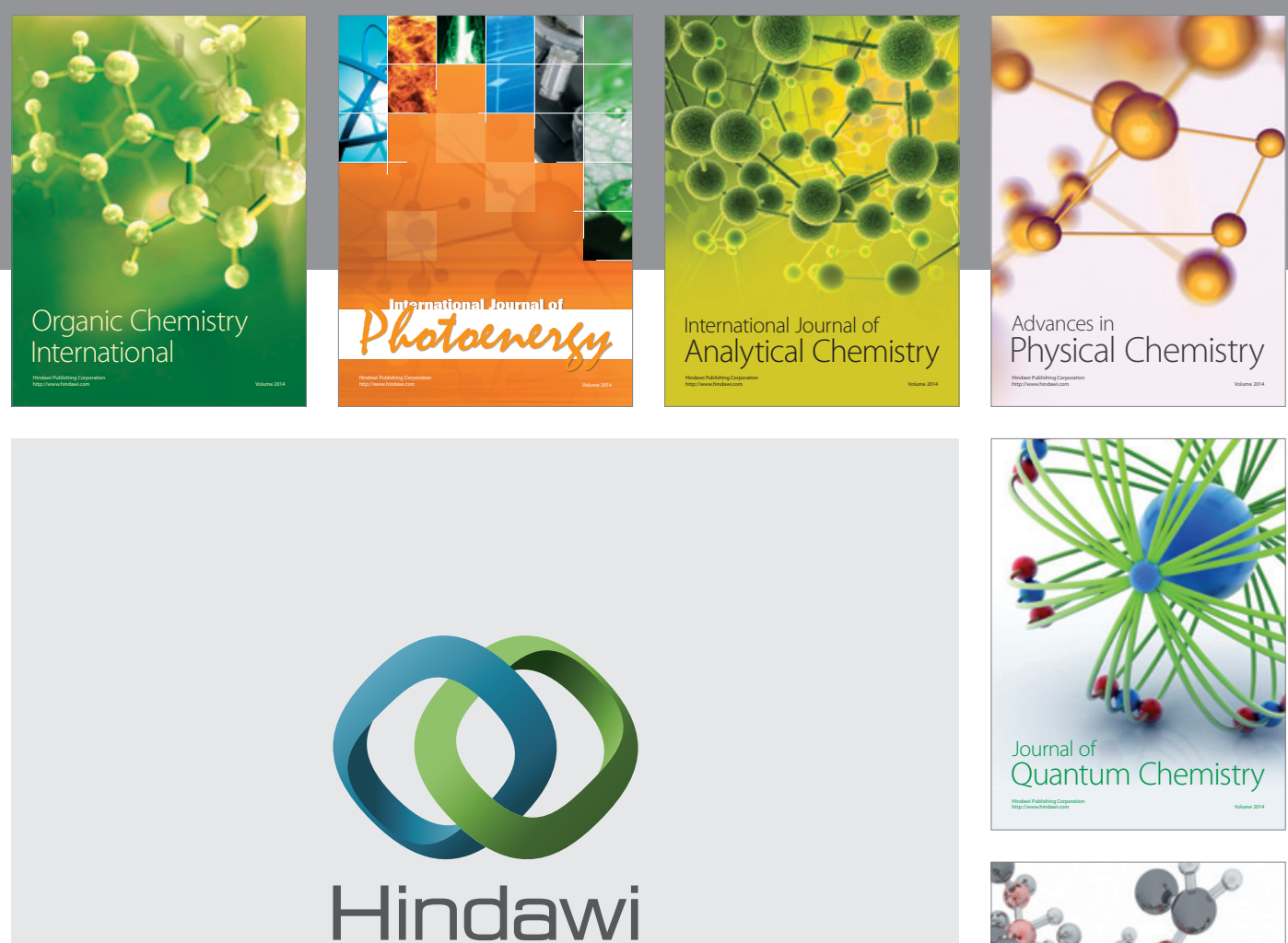

Submit your manuscripts at

http://www.hindawi.com

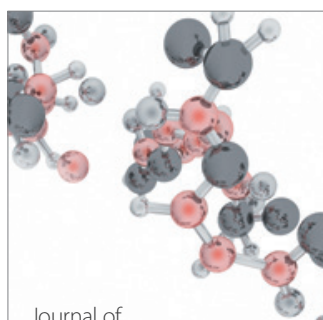

Analytical Methods

in Chemistry

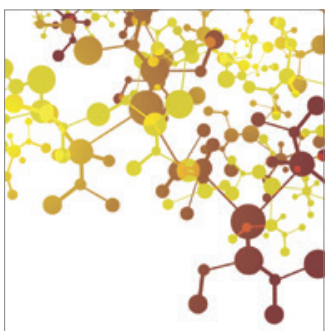

Journal of

Applied Chemistry

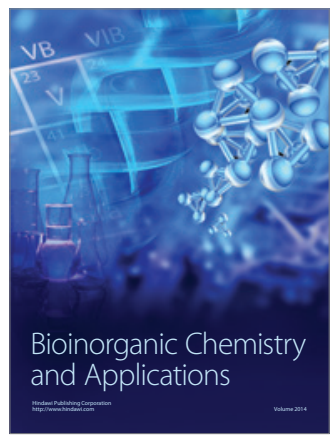

Inorganic Chemistry
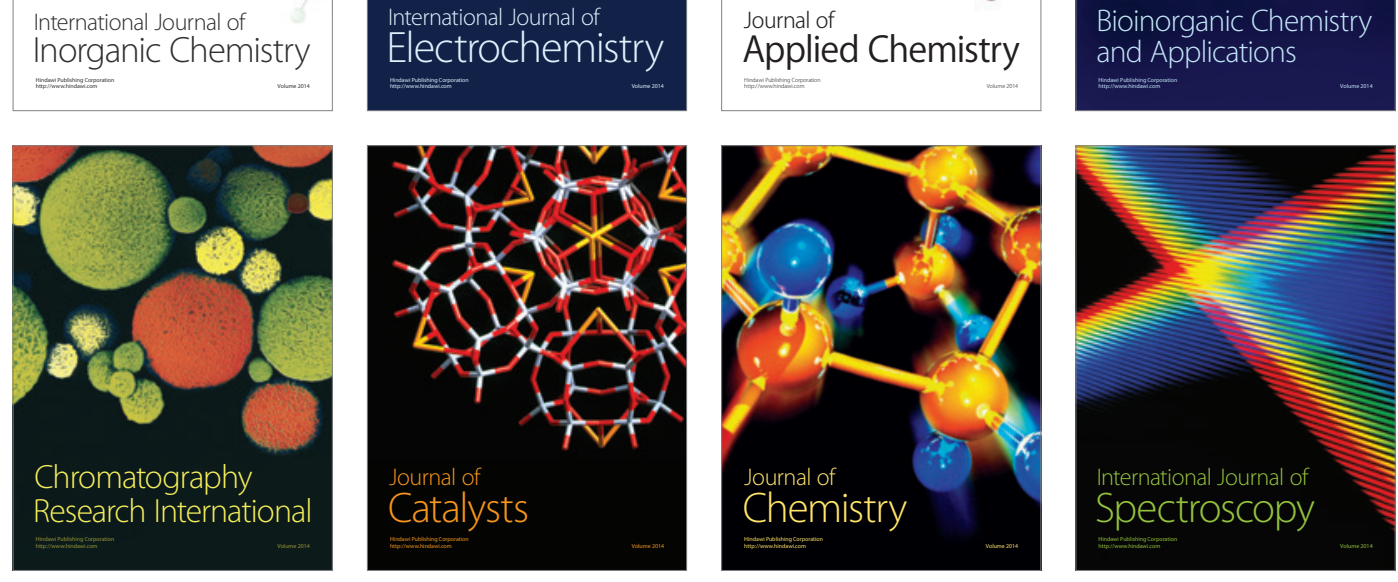